\title{
Determination of Lead Desorption from G. fisheri Seaweed Using Edible Eluents by Voltammetry at the Hanging Mercury Drop Electrode
}

\author{
Charuwan Khamkaew ${ }^{1, a *}$ and Sontaya Manaboot ${ }^{2, b}$ \\ ${ }^{1}$ Program of Chemistry, Faculty of Science and Technology, Songkhla Rajabhat University, \\ Muang District, Songkhla Province 90000, Thailand \\ ${ }^{2}$ Department of Chemistry, Faculty of Science, Prince of Songkla University, Hadyai District, \\ Songkhla Province 90112, Thailand \\ acsuitcharit@gmail.com, ${ }^{\mathrm{b}}$ mamaboot@gmail.com
}

Keywords: Lead, edible eluent, G. fisheri seaweed, DPASV, HMDE.

\begin{abstract}
A simple, rapid, selective and sensitivity approach for the determination of $\mathrm{Pb}$ (II) in G. fisheri seaweed is described. The method is based on differential pulse anodic stripping voltammetry (DPASV) at hanging mercury drop electrode (HMDE) vs. $\mathrm{Ag} / \mathrm{AgCl}$ in $0.2 \mathrm{M}$ ammonium acetate $\left(\mathrm{NH}_{4} \mathrm{OAc}\right) \mathrm{pH}$ 7.5. The operating analytical conditions; deposition potential $\left(E_{\text {dep }}\right)$ of $-0.4 \mathrm{~V}$, peak potential of $-0.78 \mathrm{~V}$, and mercury dropped size of 3 were performed. To see the sensitivity of $\mathrm{Pb}(\mathrm{II})$ measurement, the influences of deposition time and stirring speed were investigated. From the findings, the optimal parameters; deposition time of $90 \mathrm{~s}$, and stirring speed of $2000 \mathrm{rpm}$ were obtained. In these conditions, the limit of detection $(3 \sigma)$ of $0.60 \mu \mathrm{gL}^{-1}$ and the linear range extended to $12.50 \mu \mathrm{gL}^{-1}\left(r^{2}=0.9999\right)$ were obtained. The relative standard deviation (RSD) of triplicate measurements using $1.8 \mu \mathrm{gL}^{-1}$ of $\mathrm{Pb}(\mathrm{II})$ was $1.22 \%$. The method was then applied to measure $\mathrm{Pb}(\mathrm{II})$ in real samples. In this study, the desorption efficiency of edible eluents by batch method was determined. The method is based on $\mathrm{Pb}$ (II) desorption using different types of edible eluents; acetic acid (HOAc), citric acid (CTA), sodium chloride $(\mathrm{NaCl})$, sodium bicarbonate $\left(\mathrm{NaHCO}_{3}\right)$, ethylenediaminetetraacetic acid (EDTA), and chitosan (CTS). Batch desorption of $\mathrm{Pb}$ (II) from seaweed soaked in individual eluent was performed by shaking at $100 \mathrm{rpm}$ for $2 \mathrm{~h}$ at ambient temperature. Results show that the most effective eluent in desorbing the contaminated $\mathrm{Pb}$ (II) from $G$. fisheri with up to $82.2 \%$ of desorption efficiency for bound $\mathrm{Pb}$ (II) was EDTA solution.
\end{abstract}

\section{Introduction}

With the current trend in the consumption of healthy foods, seaweed is one of the natural materials using for food product processing, especially of G. fisheri seaweed due to its high amounts of nutrient elements [1]. Generally, G. fisheri is a natural sorbent to act as a biomass for desorption of heavy metals. The previous studies have been reported that G. fisheri was contaminated by heavy metals [2-3], such as lead, cadmium, zinc, manganese, arsenic, etc. Particularly of lead, it was found at somewhat higher concentrations in such seaweeds [2]. Because of $G$. fisheri contained significant amounts of nutrient elements, the consumption of seaweed products has increased as hazard to health causing from bound lead contamination [2, 4]. Therefore, the removal of lead from the seaweed prior cooking should be required. Several strong acids such as $\mathrm{HCl}, \mathrm{HNO}_{3}, \mathrm{H}_{2} \mathrm{SO}_{4}$ and chelating agent such as EDTA demonstrated as high effective eluents for removal of heavy metals from different types of seaweed by batch method [4-7]. However, those inorganic acid are inedible eluents for removal of contaminated heavy metals from edible seaweeds which were further consumed for food products.

The toxicity of lead seriously affects on health and interrupts physical development and nervous system. Therefore, the determination of lead in seaweeds is absolutely required. Many techniques, i.e. spectrometric methods and electroanalytical methods using for $\mathrm{Pb}$ (II) measurement have been reviewed [8-10]. Anodic stripping voltammetry (ASV) is electroanalytical technique, which has been applied for determination of $\mathrm{Pb}$ (II) due to inexpensive instrument and easy using on-site 
analysis with the comparison of spectrometric instruments such as atomic absorption spectrometry (AAS), inductively coupled plasma-optical emission spectroscopy (ICP-OES), inductively coupled plasma-mass spectrometry (ICP-MS), atomic fluorescence spectrometry (AFS). In this study, ASV at $\mathrm{HMDE}$ has been employed for the determination of $\mathrm{Pb}$ (II) in G. fisheri seaweed due to its high sensitivity, good selectivity and economically.

\section{Experimental}

Apparatus. Votammetric measurement made using a 797 VA-Computrace (Metrohm, Switzerland) connected to an electrode standard, 797 VA-Stand (Metrohm, Switzerland). The threeelectrode configuration comprising a Metrohm multi mode electrode (MME) in HMDE state as working electrode, a double junction $\mathrm{Ag} / \mathrm{AgCl}(3 \mathrm{M} \mathrm{KCl}$, saturated $\mathrm{Ag} / \mathrm{AgCl}$, and $3 \mathrm{M} \mathrm{KCl}$ in the bridge) reference electrode, and a Pt wire auxiliary electrode were used. All the potentials quoted are relative to the $\mathrm{Ag} / \mathrm{AgCl}$ reference electrode. A rotating Teflon rod stirred the solutions in votammetric cell or measuring vessel. The high pure mercury (99.9999\%) was used. All experiments were carried out at ambient temperature. The $\mathrm{pH}$ measurements were made with a Mettler Toledo SevenEasy S-20 pH meter (Thailand). Eppendorf reference variable micropipettes (10-100 and 100-1000 $\mu \mathrm{L}$ ) were used for pipette micro litre volume of solutions. All glassware and storage bottles were soaked overnight in $2 \mathrm{M} \mathrm{HNO}_{3}$ and thoroughly rinsed with de-ionized (DI) water before using.

Reagents and solutions. All chemicals used were of analytical grade and without further purification. High purity DI water obtained from a Milli-Q water purification system was used through-out. The stock solution of $1000 \mathrm{mgL}^{-1} \mathrm{~Pb}(\mathrm{II})$ was prepared by a careful weighting of solid lead nitrate and dissolving in DI water in $100 \mathrm{~mL}$ volumetric flask. Supporting electrolyte of $0.2 \mathrm{M}$ ammonium acetate ( $\mathrm{pH} 7.5$ ) was prepared by dissolving $1.54 \mathrm{~g}$ of $\mathrm{CH}_{3} \mathrm{COONH}_{4}$ (Merck) with $100 \mathrm{~mL}$ DI water.

Desorption study by batch method. In the study of $\mathrm{Pb}(\mathrm{II})$ desorption from G. fisheri seaweed using different types of edible eluents, i.e. HOAc, CTA, $\mathrm{NaCl}, \mathrm{NaHCO}_{3}$, EDTA, and CTS, a 1.0-g of clean dried samples was weighed into conical flask. Six sets of sample were impregnated into $75-\mathrm{mL}$ individual eluent which its concentration was controlled at $0.1 \mathrm{M}$ except for $0.2 \%(\mathrm{w} / \mathrm{v})$ of CTS. The seaweed-eluent mixtures were left on a shaker at $100 \mathrm{rpm}$ for $2 \mathrm{~h}$ at ambient temperature. Each mixture was then filtered using a domestic cotton sieve. Desorption efficiency of eluents for bound $\mathrm{Pb}$ was calculated with the following Eq. 1:

$$
\% \text { Desorption efficiency }=\frac{C_{i}-C_{f}}{C_{i}} \times 100
$$

where $\mathrm{C}_{\mathrm{i}}$ and $\mathrm{C}_{\mathrm{f}}$ were the initial and final concentrations of $\mathrm{Pb}(\mathrm{II})$ in seaweed samples, respectively. The initial concentration of $\mathrm{Pb}(\mathrm{II})$ was obtained from impregnated dried-seaweed into DI water whereas the final concentration of $\mathrm{Pb}$ (II) was obtained from desorbed dried-seaweed with the studied eluents.

Sample preparation. A portion of $1.0 \mathrm{~g}$ filtered sample was subjected to microwave digestion using a 5.0-mL of conc. $\mathrm{NHO}_{3}$ acid in tightly closed Teflon vessel which was placed in a pressure cooker. Electricity power and time programs used for domestic microwave digestion were carried out at 900 Watt for $5 \mathrm{~min}$. on high power and at 600 Watt for $10 \mathrm{~min}$. on mid-high power, subsequently. Clear solutions were then obtained and subjected to ASV measurement.

Analytical procedures. A portion of $1.0 \mathrm{~mL}$ clear solution of digested sample mixed with $10 \mathrm{~mL}$ DI water was placed into a measuring vessel, subsequently added of $1 \mathrm{~mL}$ of $0.2 \mathrm{M}$ ammonium acetate $(\mathrm{pH} 7.5)$ as supporting electrolyte solution. The mixture solution of sample was purged with oxygen free nitrogen gas (UHP 99.999\%, United Industrial Gases, Thailand) for $300 \mathrm{~s}$ to remove oxygen and other gaseous compounds before analysis. The operating analytical conditions, i.e. deposition potential: $-0.40 \mathrm{~V}$ vs. $\mathrm{Ag} / \mathrm{AgCl}$ [11], equilibration time: $5 \mathrm{~s}$, end potential: 
$-0.25 \mathrm{~V}$, voltage step: $5.6 \mathrm{mV}$, amplitude: $20 \mathrm{mV}$, frequency: $10 \mathrm{~Hz}$, sweep rate: $140 \mathrm{mV}$, and mercury dropped size: 3 were performed. A voltammogram and peak potential of $-0.78 \mathrm{~V}$ vs. $\mathrm{Ag} / \mathrm{AgCl}$ were recorded to give the sample peak current which was directly proportional to $\mathrm{Pb}$ (II) concentration. The method of standard addition was selected to use due to the matrix effects interfering. The experiments were conducted in triplicate and the means of three measurements were calculated. The procedure to evaluate the limit of detection (LOD) for ASV instrument was undertaken using 10-replicate aliquots of $\mathrm{DI}$ water to determine its $\mathrm{Pb}$ (II) concentration.

To see the sensitivity of $\mathrm{Pb}(\mathrm{II})$ measurement, the influence of two parameters, i.e. deposition time and stirring speed was investigated. The sensitivity of $\mathrm{Pb}$ (II) was considered from percent deposition efficiency of $\mathrm{Pb}(\mathrm{II})$ at mercury surface of electrode. The deposition efficiency was calculated with the following Eq. 2:

$$
\% \text { Deposition efficiency }=\frac{I_{n+1}-I_{n}}{I_{n}} \times 100
$$

where $I_{n}$ and $I_{n+1}$ were $P b(I I)$ peak currents that correspond to the investigated parameters, i.e. deposition time, and stirring speed at the order of " $n$ " and of " $n+1$ ", respectively.

\section{Results and discussion}

Effects of the variables. In order to achieve the highest sensitivity for ASV measurement, the experimental variables, i.e. deposition time, and stirring speed were optimized as below.

Influence of deposition time. The effect of deposition time on the higher the stripping peak currents for $\mathrm{Pb}$ (II) in the range of 60 to $150 \mathrm{~s}$ was studied. It is known that the higher the sensitivity for ASV measurement is based on the fact that the longer the deposition time gives the higher the peak currents. However, this fact is not strong enough to consider the highest sensitivity for measurement. Therefore, the sensitivity of $\mathrm{Pb}$ (II) was considered from percent deposition efficiency of $\mathrm{Pb}$ (II) on to mercury surface. From the investigation, the optimized deposition time obtained from the highest percent deposition efficiency of $36.62 \%$ was at $90 \mathrm{~s}$ as shown in Fig. 1. However, the decrease in deposition efficiency for deposition of $\mathrm{Pb}(\mathrm{II})$ after $90 \mathrm{~s}$ was also observed. This is due to the ion saturation at mercury surface of HMDE.

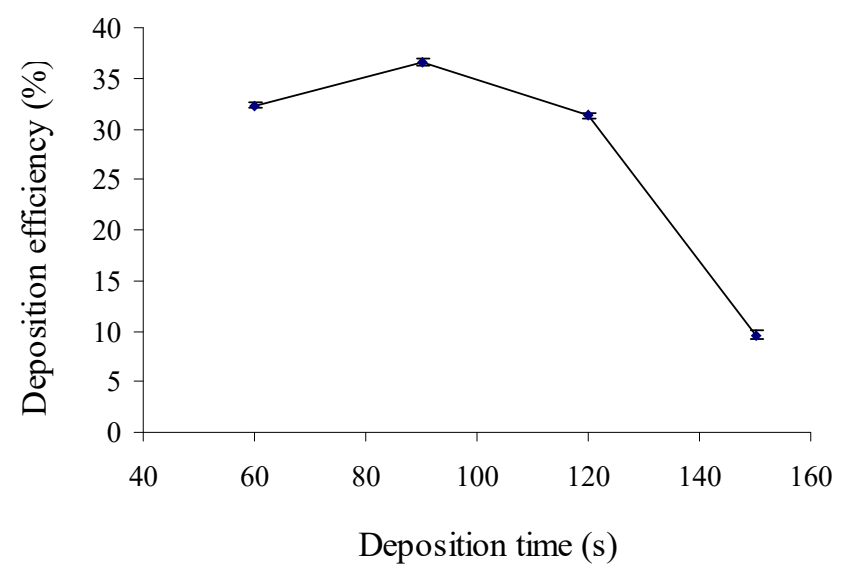

Fig. 1 Effect of deposition time on percent deposition efficiency of $\mathrm{Pb}$ (II) at mercury surface of HMDE. The working conditions for detection of $1.8 \mu \mathrm{gL}^{-1} \mathrm{~Pb}$ (II) in $0.2 \mathrm{M} \mathrm{CH}_{3} \mathrm{COONH}_{4}(\mathrm{pH}$ 7.5) are controlled at deposition potential: $-0.40 \mathrm{~V}$ vs. $\mathrm{Ag} / \mathrm{AgCl}$, peak potential: $-0.78 \mathrm{~V}$ vs. $\mathrm{Ag} / \mathrm{AgCl}$, stirring speed: $2000 \mathrm{rpm}$, and mercury dropped size: 3 .

Influence of stirring speed. The effect of stirring speed on the increase in transport of $\mathrm{Pb}$ (II) to accumulate at the mercury surface in the range of 1600 to $2400 \mathrm{rpm}$ was studied. For high accumulation rate, the solution should be stirred and the deposition potential should be much more negative $(-0.2$ to $-0.4 \mathrm{~V})$ [12]. In this study, the operating deposition potential of $-0.40 \mathrm{~V}$ vs. $\mathrm{Ag} / \mathrm{AgCl}$ was used. The transport of $\mathrm{Pb}$ (II) to mercury surface taken place by diffusion and was also 
supported by convection so that the solution should be stirred during accumulation. From the investigation, the highest percent deposition efficiency of $8.51 \%$ achieved from the stirring speed at $2000 \mathrm{rpm}$ was optimized as shown in Fig. 2. However, the ion saturation at mercury surface with corresponding to decrease in deposition efficiency was also observed when the stirring speeds over $2000 \mathrm{rpm}$ were used.

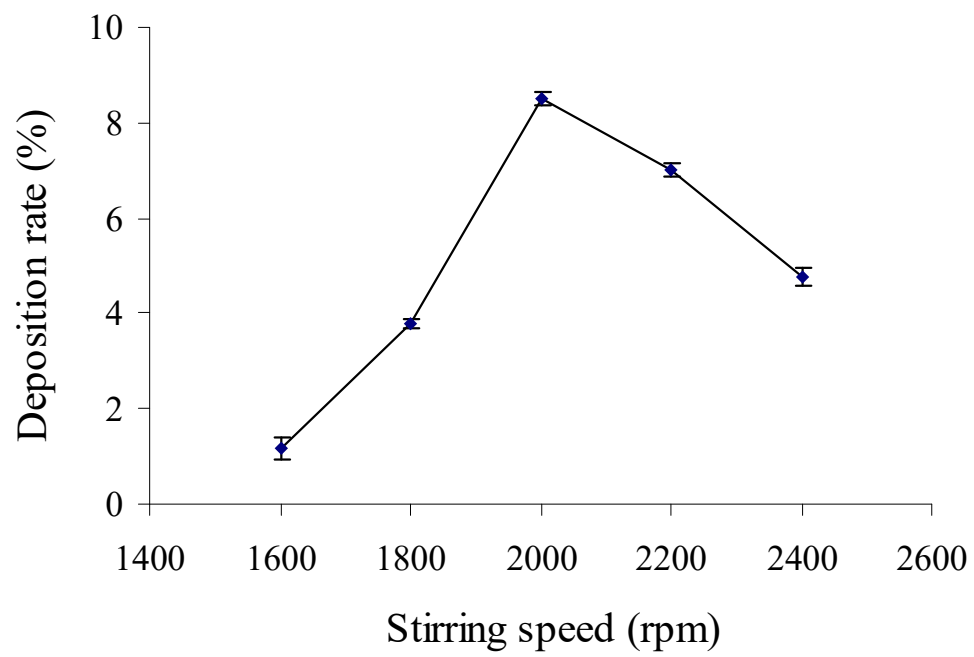

Fig. 2 Effect of stirring speed on percent deposition efficiency of $\mathrm{Pb}$ (II) at mercury surface of HMDE. The working conditions for detection of $1.8 \mu \mathrm{gL}^{-1} \mathrm{~Pb}$ (II) in $0.2 \mathrm{M} \mathrm{CH}_{3} \mathrm{COONH}_{4}(\mathrm{pH}$ 7.5) are controlled at deposition potential: $-0.40 \mathrm{~V}$ vs. $\mathrm{Ag} / \mathrm{AgCl}$, deposition time: $90 \mathrm{~s}$, peak potential: $-0.78 \mathrm{~V}$ vs. $\mathrm{Ag} / \mathrm{AgCl}$, and mercury dropped size: 3 .

Linear range, limit of detection and precision. The optimal parameters obtained from the method and the operating analytical conditions were then applied to real sample. The peak current of $\mathrm{Pb}$ (II) was proportional to its concentration. The voltammograms obtained from DPASV system for a portion solution of real samples in supporting electrolyte containing various concentrations of $\mathrm{Pb}$ (II), which was supported to compute from the standard addition method were depicted in Fig. 3A. The calibration curve in the range from 0.83 to $12.50 \mu \mathrm{gL}^{-1}$ of $\mathrm{Pb}$ (II) was then constructed by plotting peak current against $\mathrm{Pb}$ (II) concentration and the plot was depicted in Fig. $3 \mathrm{~B}$. The curve linearity with a correlation $\left(r^{2}\right)$ of 0.9999 and a slope of 5.6975 was excellent demonstrated. Under this system for triplicate measurements using $1.8 \mu \mathrm{gL}^{-1}$ of $\mathrm{Pb}(\mathrm{II})$, the reproducibility was showed the RSD of $1.22 \%$. The LOD $(3 \sigma)$ obtained was found at $0.600 \mu \mathrm{gL}^{-1}$.
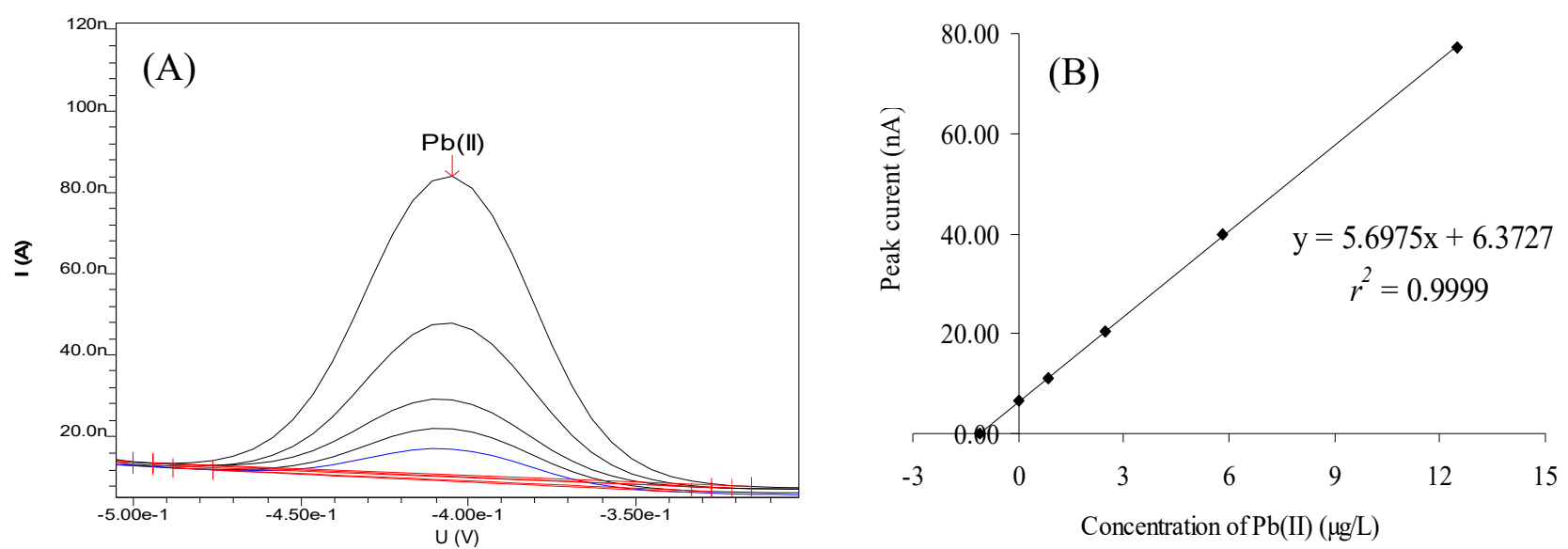

Fig. 3 Voltammograms obtained from DPASV system of $G$. fisheri seaweed in $0.2 \mathrm{M} \mathrm{CH}_{3} \mathrm{COONH}_{4}$ ( $\mathrm{pH}$ 7.5) containing various $\mathrm{Pb}$ (II) concentrations increasing from 0.83 to $12.50 \mu \mathrm{gL}^{-1}(\mathrm{~A})$, and standard addition calibration curve for the retained amount of $\mathrm{Pb}$ (II) computing in $G$. fisheri seaweed (B). 
Effect of edible eluents. According to desorption of bound $\mathrm{Pb}$ from G. fisheri seaweed is based on its desorption mechanism by desorbing eluents, the desorption efficiency of different types of edible eluents was determined. It was found that the chelating agent as $0.1 \mathrm{M}$ EDTA solution was the most effective desorption eluent for bound $\mathrm{Pb}$ from seaweed with over $82 \%$ of desorption efficiency being achieved as shown in Fig. 4. This is due to being formation of Pb-EDTA stable complex [6] for desorption mechanism better than being other Pb-eluent interactions such as being an ion exchange [6] between $\mathrm{H}^{+}$ion of acid eluents, i.e. HOAc, and CTA and $\mathrm{Pb}^{2+}$ ion, being sorption of $\mathrm{Pb}(\mathrm{II})$ through the amine functional group [13] of the CTS eluent, and being other complex formations between $\mathrm{Pb}(\mathrm{II})$ and bicarbonate or chloride [4] of the salt eluents, i.e. $\mathrm{NaHCO}_{3}$, and $\mathrm{NaCl}$, respectively.

The amounts of $\mathrm{Pb}$ (II) in seaweed samples in $\mathrm{mg} \mathrm{Kg}^{-1}$-dry weight are presented in Table 1 . The results show that $0.1 \mathrm{M}$ EDTA solution is the most effective eluent in desorbing contaminated lead from $G$. fisheri seaweed with down to $0.56 \mathrm{mg} \mathrm{Kg}^{-1}$ of $\mathrm{Pb}$ (II) being retained. The obtained amount of $\mathrm{Pb}$ (II) is lower than that of the toxic level of $1 \mathrm{mg} \mathrm{Kg}^{-1}$ seaweed product (dry weight) which was noticed from the Thai office of community product standards (CPS-55/247) for food consumption.

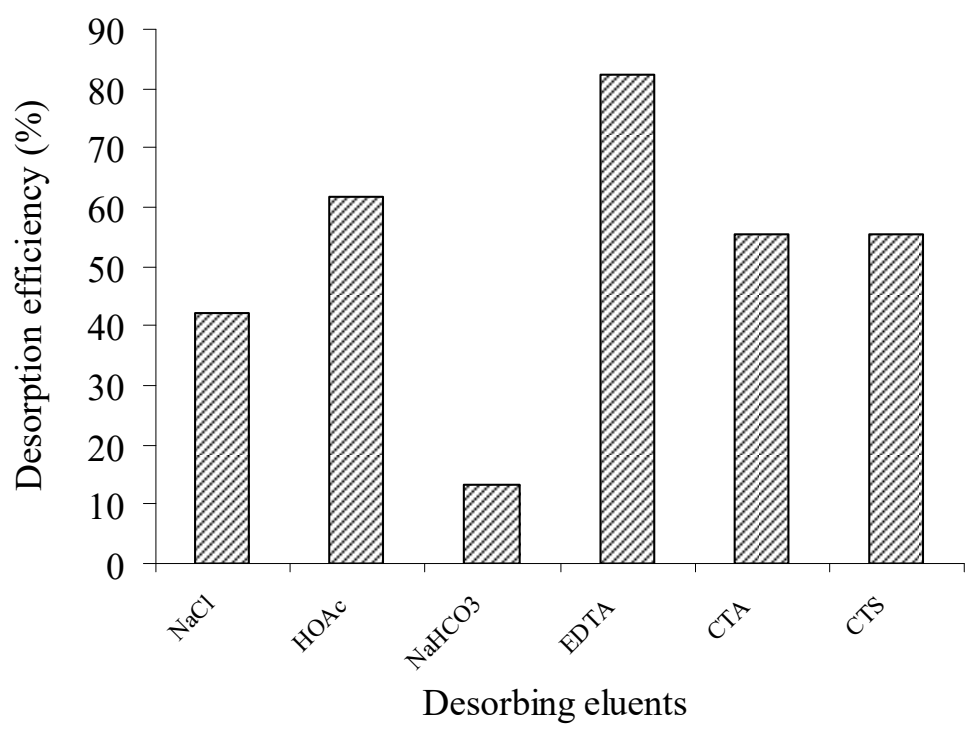

Fig. 4 Effect of desorption eluents on the percent desorption efficiency of edible eluent for bound $\mathrm{Pb}$ (II) from seaweed G. fisheri.

Table 1 Amounts of $\mathrm{Pb}(\mathrm{II})$ found in the real sample and in the desorbed sample after treatment with different types of eluent/

\begin{tabular}{lllllll}
\hline \multirow{2}{*}{$\begin{array}{l}\text { Real sample* } \\
\left(\mathrm{mg} \mathrm{Kg}^{-1} \text {-dry weight }\right)\end{array}$} & \multicolumn{5}{l}{ Desorbed samples* using different eluents $\left(\mathrm{mg} \mathrm{Kg}^{-1}-\right.$ dry weight $)$} \\
\cline { 2 - 6 } & $\mathrm{NaCl}$ & $\mathrm{HOAc}$ & $\mathrm{NaHCO}_{3}$ & EDTA & CTA & CTS \\
\hline $3.08 \pm 0.13$ & $1.69 \pm 0.09$ & $1.15 \underline{ \pm 0.10}$ & $2.61 \underline{ \pm 0.13}$ & $0.56 \underline{ \pm 0.05}$ & $1.32 \underline{ \pm 0.11}$ & $1.30 \underline{0} 0.12$ \\
\hline * Mean of triplicate measurements \pm sd. & & & & &
\end{tabular}

\section{Summary}

In this study, the determination of $\mathrm{Pb}(\mathrm{II})$ in seaweed was successfully performed by DPASV at HMDE in $0.2 \mathrm{M}$ ammonium acetate $(\mathrm{pH} 7.5)$ at deposition time of $90 \mathrm{~s}$ and stirring speed of $2000 \mathrm{rpm}$. The proposed method can be applied to measure $\mathrm{Pb}$ (II) for the determination of desorption efficiency of different edible eluents by batch method. The results of the present study conclude that $0.1 \mathrm{M}$ EDTA solution is the most effective edible eluent to remove bound $\mathrm{Pb}$ (II) from G. fisheri seaweed with regarding as suitable for cooking and further consumed for food products.

\section{Acknowledgements}

Research facilities provided by the Program of Chemistry, Faculty of Science and Technology, Songkhla Rajabhat University are gratefully acknowledged. 


\section{References}

[1] M.H. Noriziah, Y.C. Ching, Nutritional composition of edible seaweed Gracilaria changgi, Food Chem. 68 (2000) 69-76.

[2] C.V. Netten, S.A.H. Cann, D.R. Morley, J.P.V. Netten, Elemental and radioactive analysis of commercially available seaweed, Sci Total Environ. 255 (2000) 169-175.

[3] Y. Chaisuksant, Biosorption of cadmium (II) and copper (II) by pretreated biomass of marine algaGracilaria fisheri, Environ Technol. 24 (2003) 1501-1508.

[4] W.A. Stirk, J. van Staden, Desorption of cadmium and the reuse of brown seaweed derived products as biosorbents, Bot Mar. 45 (2002) 9-16.

[5] J.L. Zhou, P.L. Huang, R.G. Lin, Sorption and desorption of $\mathrm{Cu}$ and $\mathrm{Cd}$ by macro algae and micro algae, Environ Pollut. 101 (1998) 67-75.

[6] A. Hammaini, F. González, A. Ballester, M. Blázquez, J.A. Muñoz, Biosorption of heavy metals by activated sludge and their desorption characteristics, J. Environ Manage. 84 (2007) 419426.

[7] R. Gong, Y. Ding, H. Liu, Q. Chen, Z. Liu, Lead biosorption and desorption by intact and pretreated spirulina maxima biomass, Chemosphere. 58 (2005) 125-130.

[8] D. Aderhold, C.J. Williams, R.G.J. Edyvean, The removal of heavy-metal ions by seaweeds and their derivatives, Bioresource Technol. 58 (1996) 1-6.

[9] S. Abbasi, K. Khodarahmiyan, F. Abbasi, Simultaneous determination of ultra trace amounts of lead and cadmium in food samples by adsorptive voltammetry, Food Chem. 128 (2011) 254-257.

[10] C. Allan, V. dos Santos, J.C.Masini, Development of a sequential injection anodic stripping voltammetry (SI-ASV) method for determination of $\mathrm{Cd}(\mathrm{II}), \mathrm{Pb}$ (II) and $\mathrm{Cu}$ (II) in wastewater samples from coatings industry, Anal Bioanal Chem. 385 (2006) 1538-1544.

[11] C. Suitcharit C, N. Mohamed, P.E. Lim, W. Sirinawin, Determination of zinc species using ultrafiltration and different solid sorbents, J Phy Sci. (16) 2005 69-83.

[12] G.Henze, Introduction to polarography and voltammetry, Metrohm Ltd., CH-9101 Herisau, Switzerland, 2003.

[13] M.L. Cervera, M.C. Arnal, Removal of heavy metals by using adsorption on alumina or chitosan, Anal Bioanal Chem. 375 (2003) 820-825. 